INTERNATIONAL JOURNAL OF MULTidisciplinARY RESEARCH AND ANALYSis

ISSN(print): 2643-9840, ISSN(online): 2643-9875

Volume 04 Issue 11 November 2021

DOI: 10.47191/ijmra/v4-i11-09, Impact Factor: 6.072

Page No.- 1552-1554

\title{
Right Recurrent Femoral Hernia with Left Inguinal Hernia - A Case Report
}

\author{
Dr. D. B. Choksi', Dr. Karimireddy Jahnavi² , Dr. Digant Patel ${ }^{3}$, Dr. Jagrut Patel ${ }^{4}$, Dr. Rutul Shah ${ }^{5}$, Dr. \\ Sijoy Varughese ${ }^{6}$ \\ 1,2,3,4,5,6 Department of General Surgery, M.S. University Vadodara, Gujarat, India
}

\begin{abstract}
:
Introduction: Femoral hernias are a relatively uncommon type, accounting for only $3 \%$ of all hernias. While femoral hernias can occur in both males and females, they occur approximately 10 times as frequently in women than in men because of the wider bone structure of the female pelvis ${ }^{3}$. Femoral hernias develop in the upper part of the thigh near the groin just below the inguinal ligament, where abdominal contents pass through a naturally occurring weakness called the femoral canal. Femoral hernia have the highest rate of incarceration amongst groin hernia, $5 \%-20 \%{ }^{5}$

Case Presentation: A 68 year old male presented with complaints of right femoral swelling since 3 months and left inguinal swelling since 4 years.

Discussion: Femoral hernias will commonly present as a small lump in the groin. Whilst a femoral hernia is usually asymptomatic at presentation, due to the anatomy of the femoral canal, around $30 \%$ of femoral hernia cases will present as an emergency ${ }^{2}$. It is important to identify the exact location of the lump in the groin in order to decide which type of hernia is present although often, particularly in obese patients, it is not clear.

Conclusion: All patients with a femoral hernia need surgical intervention, due to the high risk of strangulation ${ }^{4}$.
\end{abstract}

KEYWORDS: Femoral hernia, groin, inguinal hernia, strangulation

\section{INTRODUCTION}

Femoral hernias occur just below the inguinal ligament, when abdominal contents pass through a naturally occurring weakness in the abdominal wall called the femoral canal. While femoral hernias can occur in both males and females, almost all develop in women due to the increased width of the female pelvis ${ }^{2}$.

Femoral hernias are more common in adults than in children. Those that do occur in children are more likely to be associated with a connective tissue disorder ${ }^{1}$. A femoral hernia will appear as a bulge near the groin or thigh.

Femoral hernia in case of male, clinically may mimic inguinal hernia; specially when hernia turns upwards and overlies medial end of inguinal canal. The exact cause of femoral are unknown most of the time. Straining can contribute to the weakening of the muscle walls. Factors that can lead to overstraining include: childbirth, chronic constipation, heavy lifting, being overweight, difficult urination due to an enlarged prostate, chronic coughing ${ }^{6}$.

Femoral hernias are initially asymptomatic until strangulation occurs so early diagnosis and treatment is very essential ${ }^{1}$. Even with obstruction or strangulation, the patient may feel discomfort more in abdomen than in femoral area. Besides this, femoral hernias are the commonest missed signs of importance by both patient and clinician.

\section{PATIENT PRESENTATION}

A 68 year old male presented with complaints of swelling over left inguinal region since 4 years and swelling over right groin since 3 months

Patient had past history of right sided femoral hernia repair 10 years back.

The patient had no complaint of abdominal pain, constipation, chronic cough, local site pain.

The patient was not a known case of DM, HTN

Patient had a past history of chronic smoking since 20 years. 


\section{Right Recurrent Femoral Hernia with Left Inguinal Hernia - A Case Report}

\section{CLINICAL FINDINGS}

On General examination patient vital signs were BP:120/78mmhg, Pulse:76 beats per minute, Respiratory rate:18 breaths per minute and temperature normal.

LOCAL EXAMINATION: On inspection there is approximately $4 \times 2 \mathrm{~cm}^{2}$ globular swelling over right groin region and $6 \times 4 \mathrm{~cm}^{2}$ globular swelling over left inguinal region, cough impulse present on both sides. On palpation both the swellings are reducible, soft in consistency, cannot get above the swelling on both sides.

On Ziemann 3 finger test, cough impulse was present at saphenous opening at right side and superficial inguinal ring at left side.

\section{INVESTIGATIONS}

Basic routine blood investigations including the total WBC count, Hemoglobin, serum creatinine and bilirubin were done and found to be normal.

$X$-ray chest and abdomen was normal.

On Ultrasound, there is approx $1.5 \mathrm{~cm}$ defect on right femoral region and $2.5 \mathrm{~cm}$ defect on left inguinal region.

\section{TREATMENT}

Under the cover of G.A, patient was operated via laparoscopically for both right femoral and left inguinal hernia using TEP procedure.

Both the hernias was reduced and approx $12 \times 15 \mathrm{~cm}^{2}$ polypropylene mesh was placed over both the hernial defects and fixed using tacker.

Post-operatively injectable antibiotics were given for 3 days, and the patient was discharged on 4 th post-operative day and kept on follow-up.

\section{FOLLOW UP AND OUTCOME}

Follow up was done on 7th post-operative day where port site dressing was done, and on 12th post-operative day where complete suture removal was done.

The patient was given oral antibiotics for 7 days post discharge along with analgesics.

No wound discharge/dehiscence/seroma formation or any other immediate post operative complications were noted.

After suture removal the patient was kept on monthly follow up for one year.

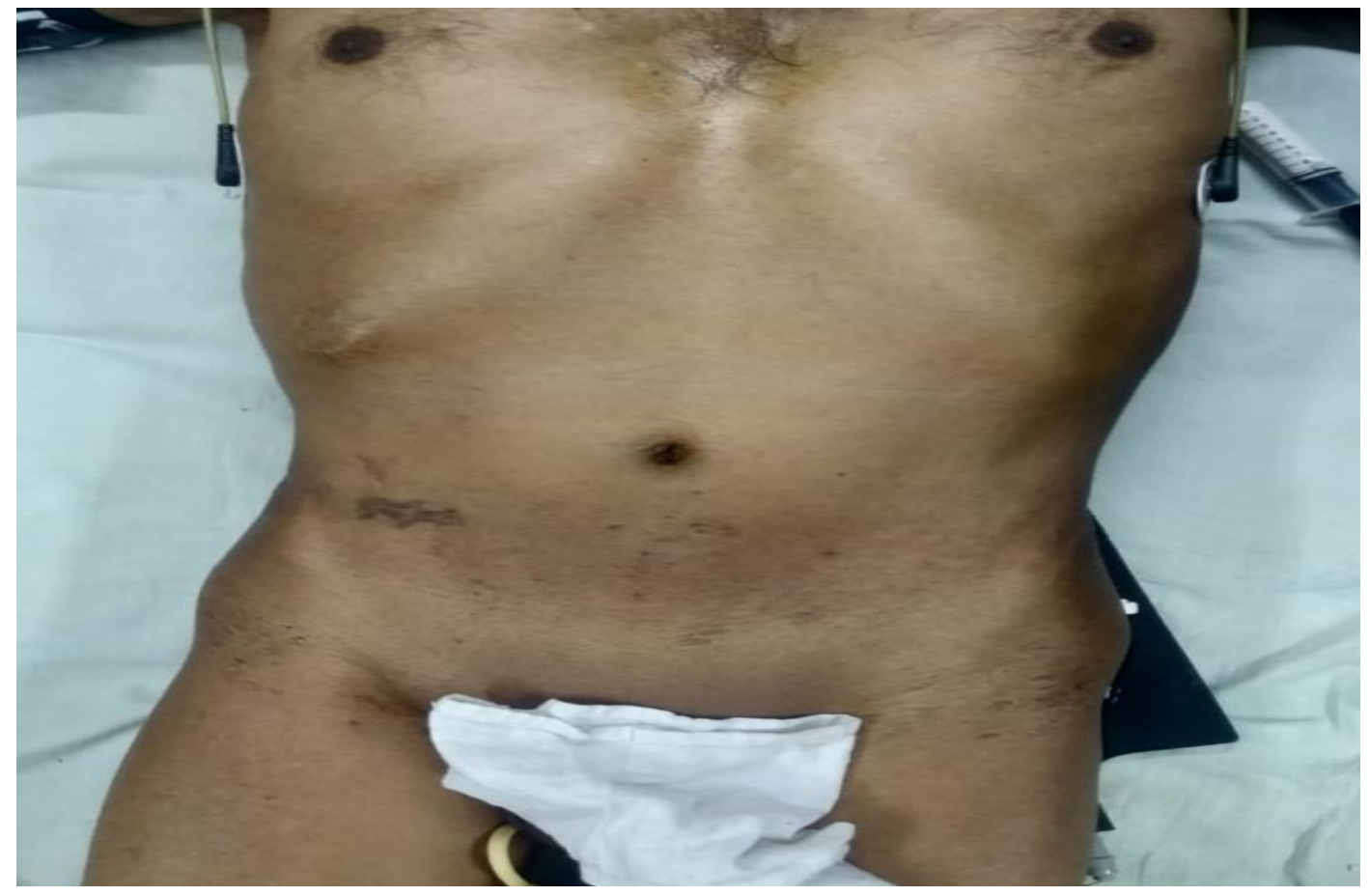

Visible right femoral hernia on supine position 


\section{Right Recurrent Femoral Hernia with Left Inguinal Hernia - A Case Report}

\section{DISCUSSION}

The femoral canal is the medial of the three compartments of the femoral sheath which is formed by a prolongation into the thigh of the fasia transversalis and of the fasia iliacus. The lateral compartment of the sheath contains the femoral artery and the intermediate one the femoral vein

Femoral canal lying within the femoral sheath is widest at its abdominal end which is femoral ring, also called internal orifice. It consists of lymph nodes (of cloquet), fat and lymphatic vessels. Through this femoral canal hernia contents descend and comes out superficially through saphenous opening. The cribriform fascia which covers the opening is thinned out in front of it. The hernia may then turn upwards and laterally to over-lie the inguinal canal.

Unlike other types of hernia, femoral hernias usually require treatment straight away due to potential complications associated with them. Surgery can be performed to put the bulge back into place and to fix the weakened abdominal wall.

Complications that can result from femoral hernias include: Obstruction where part of the bowel can become stuck in the femoral canal resulting in nausea and pain, Strangulation where the stuck section of bowel has its blood supply cut off (ischaemia), which required immediate surgical attention so that blood supply is restored and the tissue doesn't die ${ }^{2}$. The narrow femoral canal and rigid femoral ring are the main cause of bowel incarceration, strangulation and bowel resection which has been shown to have increased mortality and morbidity ${ }^{6}$.

\section{CONCLUSION}

Femoral hernias are relatively uncommon, in the above mentioned case since the patient was already operated 10 years back for femoral hernia there may be surgical failure resulting in recurrence of femoral hernia.

Exact cause of occurrence of femoral hernia in this patient at first time was not known as patient doesn't have any risk factors, there may be decreased muscle strength related to age.

\section{CONSENT}

Consent has been taken from the patient.

\section{STATEMENT OF ETHICS}

This study was performed in accordance with the ethical standards of the Committee on Human Experimentation of our institution. Patient consent was obtained for describing his clinical course in a case report.

\section{CONFLICT OF INTERESTS}

There are no conflict of interests to be declared.

\section{AUTHOR'S CONTRIBUTION}

All authors contributed equally in treatment, management and follow-up of the patient and in compilation of the case report.

\section{REFERENCES}

1) Iswanto Sucandy and Jeffrey $W$ Kolff: Incarcerated Femoral Hernia in Men: Incidence, Diagnosis, and Surgical Management, N Am J Med Sci. 2012 Nov; 4(11): 617-618., doi: 10.4103/1947-2714.103343, PMCID: PMC3503390, PMID: 23181243

2) Aloysius Ugwu-Olisa Ogbuanya, Fabian Ugonna Olisa, Richard Lawrence Ewah, Obinna Nweke, Nonyelum Benedett Ugwu: Femoral Hernia: Epidemiology and challenges of management in a sub-saharan African Country, http://nepjol.info/index.php/AJMS, DOI: 10.3126/ajms.v11i6.30368, E-ISSN: 2091-0576.

3) Tsuchiya Y, Momose H, Kure K, Ro H, Takahashi R, Okazawa Y, Kawai: Case of Incarcerated Femoral Hernia Treated with Laparoscopic Surgery after Groin Hernia Repair, Case Rep Gastroenterol 2021;15:35-40, E-ISSN: 1662-0631, https://doi.org/10.1159/000509950.

4) N C Gallegos, J Dawson, M Jarvis, M Hobsley: Risk of strangulation in groin hernias, British Journal of Surgery, Volume 78, Issue 10, October 1991, Pages 1171-1173, https://doi.org/10.1002/bjs.1800781007

5) Sudeendra Doddi, Vishal Sagar, Tarun Singhal, Santosh Balakrishnan, Frank Smedley, and Prakash Sinha: Femoral Hernia with a Twist, Volume 2010 |Article ID 650829 https://doi.org/10.1155/2010/650829

6) Majid Akrami, Mohamamd Yasin Karami, Vahid Zangouri, Iman Deilami, and Mehrnoush Maalhagh: Small Bowel Obstruction Secondary to Femoral Hernia; Case Report and Review of the Literature, Bull Emerg Trauma. 2016 Jan; 4(1): 51-53, PMCID: PMC4779471, PMID: 27162928 